\title{
Comparative Study of Advantages and Disadvantages of Endoscopic versus Conventional Myringoplasty-A Prospective Study
}

\author{
${ }^{1}$ Sachin Jain, ${ }^{2}$ Dinesh Kumar, ${ }^{3}$ Shivendra P Singh, ${ }^{4}$ Ved P Upadhyay, ${ }^{5}$ Abhishek K Dubey, ${ }^{6}$ Himani N Singh
}

\begin{abstract}
Aim: To study, the advantages and disadvantages of the endoscopic verses microscopic myringoplasty and compare the results of both the technique.

Materials and methods: This prospective study was conducted for period of 1 year from November 2016 to August 2017 on 44 patients who under-went myringoplasty. All the patients were divided in two groups. Group A, 26 patients were operated by endoscope technique and Group B, 18 patients were operated by microscope technique. All the patients were followed a 6-month for duration postoperatively.
\end{abstract}

Results: The average postoperative change in air conduction after 6 months in Group A was $8.19 \pm 4.94 \mathrm{~dB}$ and graft takeup rate was $92.31 \%$ where as it was in $10.11 \pm 5.07 \mathrm{~dB}$ and graft takeup rate was $77.77 \%$ in Group B.

Conclusion: Endoscope technique has several advantages like less hospital stay and cosmetically excellent as compared to microscopic technique but it could take more operating time and technically difficult. While patients satisfaction and graft take rate are better in microscopic technique but there was no difference in surgeon's satisfaction score.

Keywords: Endoscope, Microscope, Myringoplasty

How to cite this article: Jain S, Kumar D, Singh SP, Upadhyay VP, Dubey AK, Singh HN. Comparative Study of Advantages and Disadvantages of Endoscopic versus Conventional Myringoplasty-A Prospective Study. Int J Otorhinolaryngol Clin 2018;10(3):81-86.

\section{Source of support: Nil}

Conflict of interest: None

\section{INTRODUCTION}

Chronic suppurative otitis media (CSOM) is defined as a chronic inflammation of the mucoperiosteal lining of the middle ear cleft for more-than 3 months duration. Tympanoplasty refers to any operation involving reconstruction of the tympanic membrane and/or the ossicular chain.

\footnotetext{
${ }^{1}$ Professor and Head, ${ }^{2}$ Lecturer, ${ }^{3}$ Senior Resident, ${ }^{4-6}$ Junior Resident

${ }^{1-6}$ Department of ENT, Motilal Nehru Medical College, Allahabad, Uttar Pradesh, India

Corresponding Author: Shivendra Pratap Singh, Senior Resident, Department of ENT, Motilal Nehru Medical College, Allahabad, Uttar Pradesh, India, e-mail: shivendrapratapsingh29@gmail.com
}

Myringoplasty is a tympanoplasty without ossicular reconstruction. Over the years many methods have been used for closing perforations.

Two Otologists Wullstein ${ }^{1}$ and Zollner ${ }^{2}$ introduced operating microscope in performing otologic surgery, which improved their results significantly.The introduction of the operating microscope has significantly enhanced the outcome of myringoplasty by improving the accuracy of the technique.

In the beginning, the microscopic tympanoplasty was per-meatal overlay; however presently, the postaural underlay technique has become more popular as the permeatal approach has its limitations. The operating microscope provides a magnified image in a straight line; hence the surgeon cannot visualize the deep recesses of the middle ear in a single operating field (Dennis SP 2003). ${ }^{3}$

With the introduction of the endoscope into other branches of surgery, there have been attempts at its utilization in otology. The first published description of imaging of the middle ear by endoscopy was by Mer and colleagues (1967). ${ }^{4}$

The use of a rigid endoscope for myringoplasty has a significant advantage as it is simple to use, not only for the examination, but also for the repair of the tympanic membrane perforation. This provides a magnified vision and hence enables the surgeon to change rapidly from a close-up to a wide angle view, just by going closer or by withdrawing the scope. Further, it provides an all-round vision to the surgeon, who can rotate the angled endoscope to visualize the deep anterior canal wall, anterior recess, anterior marginal perforations, sinus tympani, facial recess, hypotympanum and the attic (Patil RN 2003). ${ }^{5}$

Endoscopic tympanoplasty follows the principles of minimal invasive surgery. Very few studies have been done previously in which endoscopes were used in ear surgery. So a study was conducted in which endoscopic myringoplasty was compared with conventional microscopic myringoplasty.

\section{AIMS AND OBJECTIVES}

To evaluate the efficacy and compare the results and postoperative complications of endoscopic myringoplasty to microscopic myringoplasty. 


\section{MATERIALS AND METHODS}

Prospective randomized comparative study was conducted in the Department of ENT, MLN Medical College and SRN Hospital, Allahabad (Uttar Pradesh) in 44 patients, subject to availability of chronic suppurative otitis media tubotympanic type with purely conductive hearing loss. Study was planned for 60 patients but due to stringent inclusion and exclusion criteria well as limited time period, only 44 patients were available for the study. This study was conducted after due clearance from the Institutional Ethics Committee.

Patients were properly informed regarding the nature of disease process, the surgical procedure including expected outcomes, potential complications and alternative treatments. Written informed consent was taken from patients before participating in the study.

Patients attending ENT OPD and giving history of CSOM of variable duration that got resolved with medication and having dry small or medium sized central perforation for at least 6 weeks duration with decreased hearing were included.

\section{Inclusion Criteria}

Patients of age group 18-40 years with dry central Small or Medium size perforation, No tympanosclerotic patch, Healthy middle ear mucosa (no granulation, edema or hypertrophy), wide external auditory canal, normal Eustachian tube function, purely conductive deafness $<40 \mathrm{~dB}$ (i.e. AC threshold of $<40 \mathrm{~dB}$ ) and No history of smoking and allergy, No medical co-morbidities like diabetes mellitus, hypertension, tuberculosis or autoimmune diseases.

\section{Exclusion Criteria}

Patients of age $<18$ years or $>40$ years with Large or subtotal perforation, abnormal eustachian tube function, COM- mucosal type with complications, CSOM- squamosal disease, with or without complications. Also patients having $\mathrm{h} / \mathrm{o}$ acute mastoiditis in past, discharging ear, previous history of ear surgery, ossicular chain necro- sis concomitant otitis externa, sensorineural hearing loss, active focus present in nose, throat, oral cavity or history of allergy. X-ray mastoid (Schuller's view) - patients having acellular mastoid.

\section{METHOD}

Patients falling in the inclusion criteria were assigned a group by computer based random table to group $\mathrm{A}$ (Microscopic assisted) and group B (Endoscopic assisted) operated by senior surgeon having experience of more than 10 years in microsurgery of ear.

Group A: It included 26 patients in which microscope assisted myringoplasty was done.
Group B: It included 18 patients in which endoscope assisted myringoplasty was done.

\section{Operative Technique (Group A)}

For conventional myringoplasty, postaural incision was made through the skin and subcutaneous tissue $2 \mathrm{~mm}$ behind the retroauricular sulcus with a temporal extension. Temporalis fascia graft was harvested, and meatotomy was done just medial to bony cartilaginous junction. Mollison's mastoid retractor was applied. The edge of perforation was freshened and the undersurface of drum remnant or annulus was denuded. Tympanomeatal flap was elevated by giving meatal skin incision at 2'o clock in right ear surgery and 6'o clock inferiorly and corresponding position in left ear. Chorda was preserved. Middle ear structures were visualized,ossicular chain integrity was checked.Middle ear was then packed with gelfoam and the graft was placed in inlay position but lateral to handle of malleus.Tympanomeatal flap was reposited in its original place,canal was filled with antibiotic soaked gelfoam. Postaural wound closed in layers. Ear canal waspacked with gelfoam and the outer meatal orifice was plugged with BIPP soaked gauze and mastoid dressing was applied.

\section{Operative Technique (Group B)}

For endoscopic myringoplasty zero degree, $17 \mathrm{~cm}$ long, and $4 \mathrm{~mm}$ thick Richard wolf make rigid endoscope was used.All surgeries were done by visualization using the Stryker's monitor. All endoscope assisted myringoplastieswere done through the permeatal route. Temporalis fascia graft was harvested by giving 2-2.5 cm incision in temporal area.Endoscope was introduced through the external auditory canal and the edges of the perforation were freshened with a sickle knife.Using a curved micro needle,the mucosa of the medial surface of the tympanic membrane remnant in the vicinity of the perforation was carefully scarified to prepare a raw recipient bed for the graft. An incision was given $8 \mathrm{~mm}$ lateral to the tympanic annulus from 10 'o clock to 6'o clock position for left ear and 6'o clock to 2'o clock position for right ear with a circular knife. The incision were extended to $2 \mathrm{~mm}$ lateral to annulus inferiorly and Notch of rivinus superiorly with the help of a flag knife.The tympanomeatal flap was elevated and placed anteriorly,ossicular chain integrity was checked. Abgel was kept in middle ear. Dried temporalis fascia graft was placed by underlay technique and the tympanomeatal flap was reposited. Gelfoam was placed in external auditory canal to stabilize the graft. Mastoid dressing was applied. 
Comparative Study of Advantages and Disadvantages of Myringoplasty

In Group A 20 patients were operated under local anesthesia and 6 patients were under general anesthesia and in Group B all 18 patients were operated under General anesthesia.

Surgeon's Satisfaction score was given between 0-10 where score $0-3$ for not satisfied, 4-7 for partially satisfied and 8-10 for fully satisfied, based on questionnaires table.

\section{Follow up}

Postoperative antibiotic, analgesics and oral decongestants with multivitamin were given for 14 days. All patients were followed up in outpatient on 7th day, 15th day, 6th week, 3rd and 6th months after surgery. Stitches was removed on 7th day and assessed for graft uptake and hearing improvement by audiometry at 6th week and 6 months postoperatively. The subjects of both groups were followed up in the given duration and the immediate as well as delayed results in terms of efficacy, benefit and postoperative complication was compared.

The outcome was taken as-

- Successful: If neotympanic membrane was intact and mobile at the end of 6 months.

- Failure: If there was graft rejection before or at 6 months postoperatively.

Subjective assessment of the patients for cosmetic results was done based on different questionnaires in both the groups.

Patient's Satisfaction score was assessed between 0-10 where score $0-3$ was given for not satisfied, $4-7$ for partially satisfied and 8-10 for fully satisfied, based on questionnaires table.

\section{RESULTS}

The age of the patients varied between 18 years and 40 years i.e. the youngest patient was 18 years and the eldest was 40 years and male to female ratio was 1:1. Maximum number of patients (35 out of 44) had air conduction level ranges $31-40 \mathrm{~dB}$ (Table 1).

In all 26 cases of group A, postaural approach with temporalis fascia graft was used and all the patients were operated by using inlay technique of myringoplasty. In Group B, all 18 cases were operated through endomeatal approach. Temporalis fascia graft was placed by using inlay technique of myringoplasty.

Table 1: Air conduction threshold in 44 patients of group $A$ and $B$

\begin{tabular}{llll}
\hline $\begin{array}{l}\text { Air conduction } \\
\text { (in } d B) \\
\text { threshold }\end{array}$ & $\begin{array}{l}\text { Group } A \\
\text { (Microscopic) } \\
(n=26)\end{array}$ & $\begin{array}{l}\text { Group B } \\
(\text { Endoscopic) } \\
(n=18)\end{array}$ & $\begin{array}{l}\text { Total no of } \\
\text { cases }\end{array}$ \\
\hline $10-20$ & 00 & 01 & 01 \\
$21-30$ & 04 & 04 & 08 \\
$31-40$ & 22 & 13 & 35 \\
\hline
\end{tabular}

Table 2: Operating time in surgery in Group A and B

\begin{tabular}{lllll}
\hline Time (Minutes) & \multicolumn{2}{l}{$\begin{array}{l}\text { Group A } \\
\text { (Microscopic) }\end{array}$} & \multicolumn{2}{l}{$\begin{array}{l}\text { Group B } \\
\text { (Endoscopic) }\end{array}$} \\
\cline { 2 - 5 } & $\mathrm{n}=26$ & $\%$ & $\mathrm{n}=18$ & $\%$ \\
\hline $40-60$ & 12 & 46.16 & 4 & 22.33 \\
$61-80$ & 10 & 38.46 & 8 & 44.43 \\
$81-100$ & 2 & 7.69 & 4 & 22.23 \\
$101-120$ & 2 & 7.69 & 2 & 11.11 \\
\hline Average Time & $68.69 \pm 15.85$ & & $73.06 \pm 18.40$ \\
(in minutes) & & & &
\end{tabular}

Table 3: Postoperative stay in hospital in Group A and B

\begin{tabular}{lll}
\hline Duration (In days) & $\begin{array}{l}\text { Group A (Micro- } \\
\text { scopic) }(n=26)\end{array}$ & $\begin{array}{l}\text { Group B (Endo- } \\
\text { scopic) }(n=18)\end{array}$ \\
\hline $0-1$ & 2 & 3 \\
$2-3$ & 8 & 13 \\
$>3$ & 16 & 2 \\
& & $2.78 \pm 1.44$ \\
$\begin{array}{l}\text { Average time (in } \\
\text { days) (Mean } \pm \text { SD) }\end{array}$ & $5 \pm 2.23$ & \\
\hline
\end{tabular}

Table 4: Graft status in Group A and B $(\mathrm{n}=44)$

\begin{tabular}{llll}
\hline Group & Success & Failed & $P$ value \\
\hline Group A & $24(92.31 \%)$ & $2(7.69 \%)$ & 0.3503 \\
Group B & $14(77.77 \%)$ & $4(22.23 \%)$ & 0.3503 \\
\hline
\end{tabular}

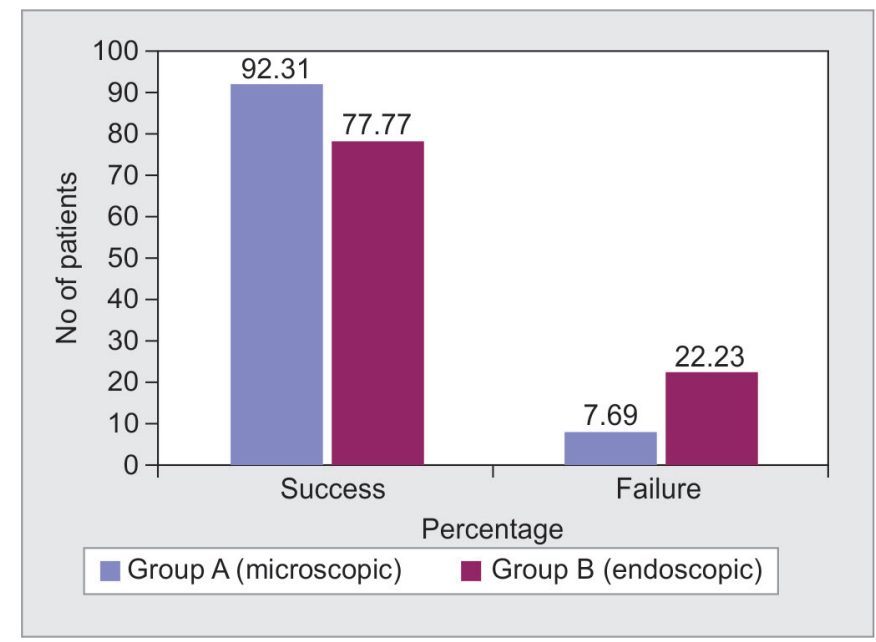

Fig. 1: (Graft status in Group A and B) $(n=44)$

Average operating time was $68.69 \pm 15.85$ min (mean \pm SD) in Group A and $73.06 \pm 18.40$ min (mean \pm SD) in Group B (Table 2).

Average hospital stay time in group A was $5 \pm 2.23$ days (mean $\pm \mathrm{SD}$ ) while average hospital stay time in group B was $2.78 \pm 1.44$ days (mean $\pm \mathrm{SD}$ ) (Table 3 ).

At the end of 6 months follow-up graft take up rate in group A and group B were $92.31 \%$ and $77.73 \%$ respectively (Table 4 and Figure 1).

It was seen that gain in hearing after 6 weeks and 6 months was same. The average postoperative change in air conduction at 6 weeks and 6 months in Group A was 
Table 5: Mean postoperative gain in hearing in Group A and Group B

\begin{tabular}{|c|c|c|c|c|}
\hline \multirow[t]{2}{*}{ Groups } & \multirow[t]{2}{*}{$\begin{array}{l}\text { Preoperative air conduction } \\
\text { (mean } \pm S D)\end{array}$} & \multicolumn{2}{|c|}{$\begin{array}{l}\text { Postoperative air conduction } \\
(\text { mean } \pm S D)\end{array}$} & \multirow[t]{2}{*}{$\begin{array}{l}\text { Change in air conduction } \\
\text { (mean } \pm S D)\end{array}$} \\
\hline & & 6 weeks & 6 months & \\
\hline $\begin{array}{l}\text { Group A } \\
\text { (Microscopic) }(n=26)\end{array}$ & $36.42 \pm 3.87$ & $29.42 \pm 8.20$ & $29.42 \pm 8.20$ & $8.19 \pm 4.94$ \\
\hline $\begin{array}{l}\text { Group B } \\
\text { (Endoscopic) }(n=18)\end{array}$ & $34.33 \pm 6.37$ & $26.11 \pm 5.14$ & $26.11 \pm 5.14$ & $10.11 \pm 5.07$ \\
\hline$p$ value & 0.1830 & 0.1370 & 0.2172 & \\
\hline
\end{tabular}

Table 6: Patient satisfaction score in Group A and B

\begin{tabular}{|c|c|c|c|c|}
\hline \multirow[t]{2}{*}{$\begin{array}{l}\text { Satisfaction } \\
\text { score }\end{array}$} & \multicolumn{2}{|c|}{$\begin{array}{l}\text { Group A } \\
\text { (Microscopic) }\end{array}$} & \multicolumn{2}{|c|}{$\begin{array}{l}\text { Group B } \\
\text { (Endoscopic) }\end{array}$} \\
\hline & No. & $\%$ & No. & $\%$ \\
\hline $\begin{array}{l}\text { Not satisfied } \\
(0-3)\end{array}$ & 4 & 15.38 & 4 & 22.22 \\
\hline $\begin{array}{l}\text { Partially } \\
\text { satisfied (4-7) }\end{array}$ & 4 & 15.38 & 2 & 11.11 \\
\hline $\begin{array}{l}\text { Fully satisfied } \\
(8-10)\end{array}$ & 18 & 69.24 & 12 & 66.66 \\
\hline
\end{tabular}

$8.19 \pm 4.94 \mathrm{~dB}$, where as it was in $10.11 \pm 5.07 \mathrm{~dB}$ in Group B (Table 5).

Patients presented with postoperative complications like wound gaping in 2/26 (7.69\%) in Group A while none in Group B. At the end of 6 months all (100\%) patients in the endoscope group rated their cosmetic result as excellent whereas in the microscopic group $10(38.46 \%)$ patients rated their cosmetic result as excellent, $12(46.15 \%)$ patients rated their cosmetic result as satisfactory and 4(15.38\%) patients rated their cosmetic result as poor.

In group A patient fully satisfied (score 7-10) in 18/26 (69.24\%) and 12/18 (66.66\%) in Group B and not satisfied (score 0-3) in 4/26 (15.38\%) in Group A and 4/18(22.22\%) in Group B (Table 6).

\section{DISCUSSION}

In our study mean age of patients in Group A was 29.23 \pm 6.72 years (mean \pm SD) and in Group B it was $31.06 \pm$ 6.24 years (mean $\pm \mathrm{SD}$ ); which ranged between $18-40$ years, which was comparable with other studies. ${ }^{6,7}$ This dif- ference in age between the two groups was statistically insignificant. So age will not be a factor influencing the result in our two groups. In other studies age varied from 7 years to 82 years (Table 7 ). ${ }^{8-14}$

In study of $\mathrm{A}$ Raj et al. ${ }^{15}$ range of age distribution was not specified. When we compared Group A with Group B, it was observed that male and female patients were equal. In some studies ${ }^{16-18}$ male patients were more, while in other studies ${ }^{19,20}$ female patients were more. Many authors did not specify male female ratio. ${ }^{17,21}$ In present study like other studies, sex of patients did not influence the results.
In our study average operating time was $68.69 \pm$ 15.85 in Group A and $73.06 \pm 18.40$ in Group B, which showed that endoscopic myringoplasty apparently took more time than microscopic myringoplasty which was due to difficulty in graft placement because only one hand was free to manipulate the graft. But there was no statistical significant difference in time in between two groups ( $p$ value $>0.05$ ) which was comparable with other studies. ${ }^{7,16,18,20}$ However in few studies microscopic group operating time was more. ${ }^{3,17,19}$ Some studies did not mention operating time. $6,17,21$

It was seen that the postoperative stay time was significantly shorter in Group B (2.78 \pm 1.44 days $)$ as compared to Group A ( $5 \pm 2.23$ days).The difference was statistically insignificant $(p$ value $=0.0006$ ). It was due to less post op complications like pain, nausea, vomiting and minimal requirement of dressing and wound care in Group B. Our study was comparable with other studies. ${ }^{7,16}$ However in many studies hospital stay time was not mentioned. $3,6,17-19,22$

In our study graft take up rate in Group A and Group B were $92.31 \%$ and $77.73 \%$ respectively, but there was no statistically significant difference ( $p$ value $=0.3503$ ). Our study is comparable with other studies (Table 7). 3,6,7,16-22 Our study further signifies that graft take up rate was comparable in both the techniques.

In our study there was no difference in gain in hearing in both the groups $(\mathrm{A}=8.19 \pm 4.94 \mathrm{~dB}$ Vs $\mathrm{B}=10.11 \pm$ 5.07dB). It was comparable with other studies. 7,17-19,21,22 However many studies did not specify this., $3,6,16,20$

Endoscopic myringoplasty is an emerging technique and with further expertise in use of endoscope for myringoplasty and use of endoscope holders to make the second hand free will make this technique easier and will be technique of future.

\section{CONCLUSION}

Endoscope technique has several advantages like less hospital stay and cosmetically excellent as compared to microscopic technique but it could take more operating time and technically difficult. While patients satisfaction and graft take rate are better in microscopic technique but there was no difference in surgeon's satisfaction score. 


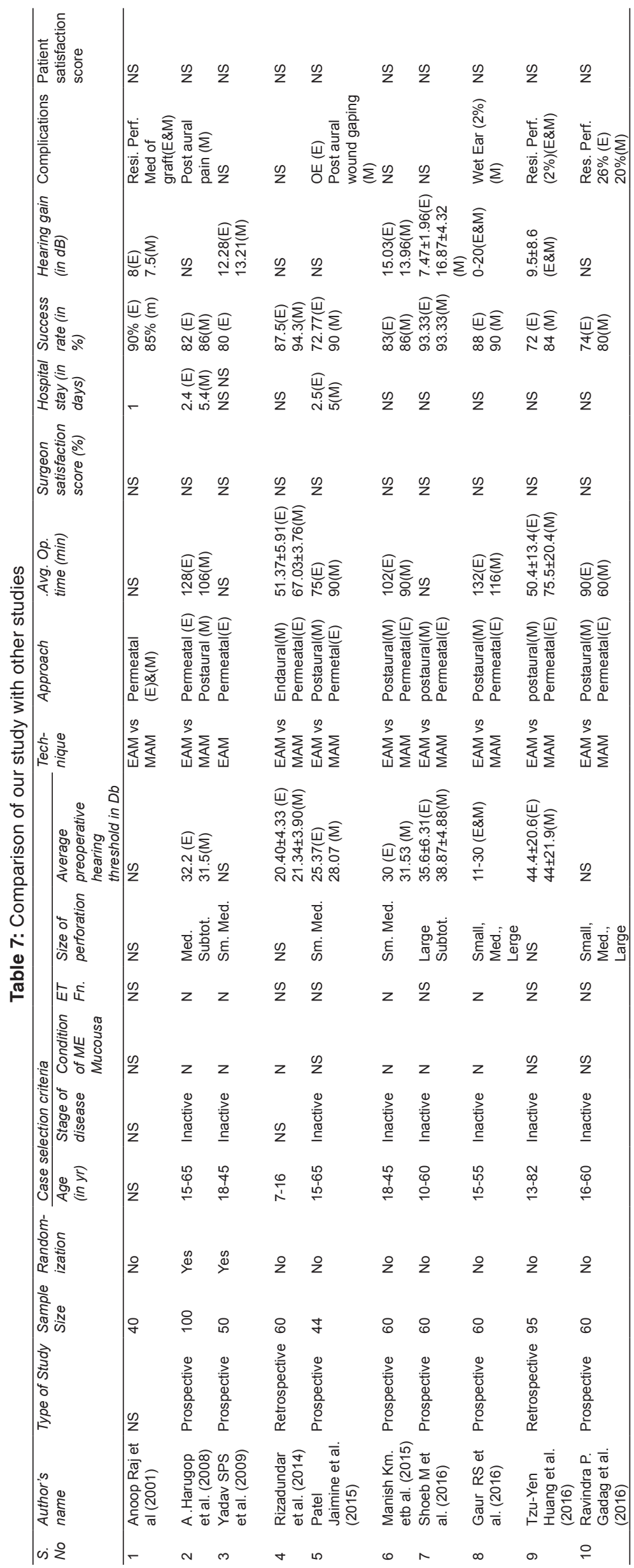




\section{REFERENCES}

1. Wullstein H, Theory And Practice Of Myringoplasty. Laryngoscope.1956;66:1076-1093.

2. Zollner F, The Principles Of Plastic Surgery Of The SoundConducting Apparatus, J Laryngol Otol. 1955;69:637-652.

3. Dennis SP.Endoscopic assisted middle ear surgery. In:Glasscock ME III Gulya Aj;Surgery of the ear. $5^{\text {th }}$ ed. Hamilton:Elsevier.2003;Vol 5:325-334.

4. Mer SB, Derbyshire AJ, Brushenko A, PontarelliDA.Fiberoptic endoscopes for examining the middle ear; Arch Otolaryngol. 1967, 85 (4):387-393.

5. Patil RN. Endoscopic tympanoplasty- Definitely advantageous (preliminary reports). Asian J Ear Nose Throat. 2003; Vol 25:9-13.

6. Bottrill ID, Poe DS: Endoscope-assisted ear surgery. Am J Otol 1995;161:158-163.

7. Migirov L, Shapiro Y, Horowitz Z, Wolf M. Exclusive Endoscopic Ear Surgery for Acquired Cholesteatoma: Preliminary Results.Otol Neurotol2011;32:433-436.

8. Harugop A, Mudhol R, Godhi R. A comparative study of endoscope assisted myringoplasty and micrsoscope assisted myringoplasty. Indian Journal of Otolaryngology and Head Neck Surgery. 2008;60 (4):298-302.

9. Yadav S P S, Aggarwal N, Julaha M, Goel A. Endoscopeassisted myringoplasty. Singapore Med J. 2009; 50(5): 510.

10. Patel J, Aiyer RG, Gajjar Y, Gupta R, Raval J,Suthar PP. Endoscopic tympanoplasty vs microscopic tympanoplasty in tubotympanic CSOM. Int J Res Med Sci. 2015; 3(8): 1953-1957.

11. Kumar M, Kanaujia SK, Singh A: To evaluate the efficacy of endoscopic myringoplasty. Int J Otorhinolaryngol Clin. 2015; 7(3).132-137.
12. Shoeb M, Gita V, Bhargava S, Mhashal S. Comparison of surgical outcomes of tympanoplasty assisted by conventional microscopic method and endoscopic method .Int J otorhinolaryngol Head Neck Surg. 2016 ; 2(4):184-188.

13. Gaur RS, Tejavath P, Chandel S. A comparative study of microscopic -assisted and endoscopic-assisted myringoplasty. Indian J Otol. 2016; 22:177-182.

14. Gadag RP, Godse A, Narasaiah MD, Shetty N, Prajna L. Comparative study of outcomes of microscopic versus endoscopic myringoplasty. MedicaInnovatica.2016; 5(1): 3-6.

15. Raj A, Meher R. Endoscopic transcannalmyringioplasty - A study. Indian Journal of Otolaryngology and Head and Neck Surgery. 2001; Vol 53:47-49.

16. Booth JB. Myringoplasty factors affecting results. Final report: Journal of Laryngology and Otolgy 1973 Nov;87:1039-1084.

17. Cable HR. Surface tension and temporalis fascia grafts. The Journal of Laryngology and Otology 1981 Jul;95:667-673.

18. Derlacki EL. Repair of central perforations of tympanic membrane. Archives of Otolaryngology 1953;58:405-420.

19. Eichner H.Eline mother-and baby-scope-optic zur trammelfell-und mittelohr-endoskopie. Laryngol Rhinol Otol(Stuttg) 1978;57:872-876.

20. Monatsschr Ohrenheilkd Laryngorhinol. 1953 Oct-Dec; 87(4):308-1.1

21. Ayache S, Tramier B, Strunski V.Otoendoscopy in Cholesteatoma urgery of the Middle Ear: What Benefits Can Be Expected? Otol. Neurotol.2008;29:1085-1090

22. Michael MD. Homograft tympanic membrane in myringoplasty. Annals of Otol Rhinol Laryngol 1972;81:194-202. 